\title{
FORMAÇÃO E ATUAÇÃO SINDICAL: COMO OS PROCESSOS DE FORMAÇÃO CONTRIBUEM PARA O EMPODERAMENTO DAS MULHERES NO MEIO RURAL
}

\author{
TRAINING AND UNION ACTIVITIES: HOW THE TRAINING PROCESSES \\ CONTRIBUTE TO THE EMPOWERMENT OF WOMEN IN RURAL AREAS
}

\author{
Taise Pasa ${ }^{1}$ \\ Jane Francisca Richter da Costa ${ }^{2}$ \\ Zenicléia Angelita Deggerone ${ }^{3}$
}

\begin{abstract}
Resumo: Este artigo apresenta a experiência de capacitação social proporcionado pelo projeto de extensão Formação e Atuação Sindical: como os processos de formação contribuem para o empoderamento das mulheres no meio rural, organizado pelo Coletivo de Mulheres do Sindicato Unificado dos trabalhadores na Agricultura Familiar (SUTRAF-AU) e a Universidade Estadual do Rio Grande do Sul (UERGS). As atividades do projeto ocorreram entre os meses de maio a dezembro de 2017 para 28 mulheres agricultoras familiares que atuam em 15 municípios de base sindical do SUTRAF-AU. O projeto de extensão propiciou às mulheres informação e formação nos seguintes temas: os impactos da nova proposta do regime de previdência social para as mulheres; o papel do coletivo de mulheres na liderança e motivação no trabalho comunitário; as desigualdades de gênero existentes na sociedade; a importância do autoexame e da prevenção de doenças; a sensibilização socioambiental por meio da separação e reutilização adequada de resíduos e a geração de renda por meio do resgate de artesanatos rurais. Por fim, infere-se que este projeto de extensão propiciou condições para que as mulheres sejam as protagonistas de uma nova geração, na busca constante por empoderamento para reduzir as desigualdades de gênero existentes meio rural.
\end{abstract}

Palavras-chave: Agricultoras familiares. Empoderamento. Capacitação.

Abstract: This article presents the experience of social empowerment provided by the extension project Training and union activities: how the training processes contribute to the empowerment of women in the rural environment, organized by the Women's Collective of the Unified Union of Workers in Family Farming (SUTRAF-AU) and the State University of Rio Grande do Sul(UERGS). The project activities took place between May and December 2017, for 28 women family farmers, who work in 15 municipalities of the union base of the (SUTRAF-AU). The extension project provided women with information and training on the following themes: the impacts of the new proposal on the social security scheme for women; the role of the women's collective in the leadership and motivation of community

\footnotetext{
${ }^{1}$ Bacharel em Administração, pela Universidade Estadual do Rio Grande do Sul, Unidade Erechim, Erechim, Rio Grande do Sul, Brasil. Orcid:0000-0001-5540-0907 E-mail: taise-pasa@uergs.edu.br

${ }^{2}$ Especialista em Sociedade, Ambiente e Desenvolvimento, pela Universidade Estadual do Rio Grande do Sul, Unidade Erechim, Erechim, Rio Grande do Sul, Brasil. Orcid: 0000-0003-4031-631X E-mail: richter_jane@yahoo.com.br

3 Doutora em Desenvolvimento Rural, pela Universidade Estadual do Rio Grande do Sul. Professora da Universidade Estadual do Rio Grande do Sul, Unidade Erechim, Erechim, Rio Grande do Sul, Brasil. Orcid: 00000003-4286-4686 E-mail: zenicleia-deggerone@uergs.edu.br
} 
work; the existing gender inequalities in society; the importance of self-examination and disease prevention; social and environmental awareness through the proper separation and reuse of waste and the generation of income through the rescue of rural handicrafts. Finally, it is inferred that this extension project provided conditions for women to be protagonists of a new trend, in the constant search for empowerment to reduce gender inequalities in rural areas.

Keywords: Family Farmers. Empowerment. Training.

\section{Introdução}

O processo de organização política e de desenvolvimento, a partir da perspectiva de gênero, vem ganhando destaque nos espaços produtivos, econômico-sociais e acadêmicos. Historicamente, as mulheres ocuparam lugares de menos destaque dentro da sociedade, especialmente no meio rural, porém, com apoio de organizações sociais, políticas, sindicais e da própria união das mulheres, esse contexto foi sendo modificado. Como exemplo desse processo, Siqueira (2014) salienta que, no Brasil, a agricultura familiar exerce grande importância para a economia interna e o abastecimento de alimentos no país, e as mulheres desempenham um papel de protagonismo, mas que socialmente esta atuação passa despercebida, devido ainda à dominação masculina.

Frente a este cenário, as organizações sindicais possuem uma história de resistência e oposição a estas situações. Por meio de uma estrutura sindical desafiadora, as participantes do Coletivo iniciaram um processo de organização social, com o objetivo de mobilizar e capacitar um número maior de mulheres para atuar em coletivos organizados e dirigidos por agricultoras familiares. A exemplo disso, na Região Alto Uruguai, porção Norte do Estado do Rio Grande do Sul, as atividades econômicas estão baseadas no trabalho familiar, na policultura, e possuem um histórico de sindicalismo que busca representar a agricultura familiar por meio do Sindicato Unificado dos Trabalhadores na Agricultura Familiar do Alto Uruguai (SUTRAF-AU).

Essa organização sindical e social promoveu espaços para a discussão de gênero, principalmente no que se referem à busca pela equiparação de oportunidades, à construção de políticas públicas e ao reconhecimento social da mulher. Segundo Melo e Lopes (2012), empoderar as mulheres é colaborar com a igualdade de gênero e instituir mudanças nas bases estruturais da sociedade, envolvendo as famílias, escolas e expandindo para o âmbito social. Além disso, para os autores somente a formação possibilita a aquisição da emancipação individual e também da consciência coletiva necessária para a superação da dependência social 
e dominação política (MELO; LOPES, 2012).

Dessa forma, os processos de formação contribuem para o desenvolvimento individual das mulheres nos diferentes espaços de sociabilidade e condiciona para a apropriação de diversos conhecimentos. A formação se refletirá na construção de capacidades individuais melhorando a gestão de suas atividades produtivas, econômicas, possibilitando uma maior consciência de sua capacidade de influenciar outras pessoas e de tomar decisões sobre a gestão e organização dos empreendimentos rurais e sobre sua própria vida.

Considerando a importância da organização das mulheres e dos processos de formação, este artigo tem por objetivo apresentar a experiência da capacitação social proporcionada pelo Projeto de Extensão "Formação e Atuação Sindical: como os processos de formação contribuem para o empoderamento das mulheres no meio rural", organizado pelo Coletivo de Mulheres do Sindicato Unificado dos Trabalhadores na Agricultura Familiar (SUTRAF-AU) e a Universidade Estadual do Rio Grande do Sul (UERGS), Unidade em Erechim.

Os objetivos específicos deste trabalho buscam:

- apresentar os eixos norteadores e as etapas do processo de formação organizados pela Universidade Estadual do Rio Grande do Sul e o Coletivo de Mulheres do SUTRAF-AU;

- destacar os aspectos positivos que a capacitação propiciou na organização social das participantes;

- apresentar as dificuldades que as mulheres identificaram ao participar do processo formativo.

Para atender ao objetivo deste artigo, o presente trabalho apresenta a metodologia utilizada na execução do projeto de extensão, o aporte teórico, que destaca a importância da inclusão social das mulheres para a construção de espaços de igualdade na sociedade, os resultados e discussão a partir da execução do projeto, como os processos formativos contribuem para o engajamento das mulheres no desenvolvimento local, e, por fim, são apresentadas as principais conclusões acerca deste trabalho.

O projeto de extensão foi desenvolvido por meio de uma parceria formada entre a UERGS, Unidade em Erechim, com o SUTRAF-AU para oferecer um curso de capacitação com o propósito de formar multiplicadores de informações e conhecimentos na agricultura familiar. Inicialmente, o SUTRAF-AU realizou a divulgação do curso e as inscrições das agricultoras familiares interessadas em ser uma multiplicadora de conhecimentos em seus municípios de atuação. O deslocamento das mulheres que participaram das sedes municipais

\footnotetext{
\begin{tabular}{l|l}
\multirow{2}{*}{ REVISTA } & EXTENSÃO \& CIDADANIA \\
\cline { 2 - 3 } & v. 8, n. 14, p. 93-107, jul./dez. 2020. ISSN 2319-0566
\end{tabular}
} 
até a cidade de Erechim e a alimentação foi organizado de forma solidária entre os sindicatos municipais. Já a UERGS ofereceu a infraestrutura (salas de aulas) para desenvolver as atividades, bem como os professores e outros profissionais colaboradores que ministraram as oficinas e palestras no projeto de extensão.

As oficinas tiveram a duração de 8 horas e ocorreram entre os meses de maio a dezembro de 2017, foram abordados diversos temas relevantes para o desenvolvimento e alto senso de reconhecimento das mulheres agricultoras familiares. A metodologia utilizada para o desenvolvimento dos encontros foi a oficina pedagógica que, segundo Freire (1998), é um método que permite a atuação democrática e participativa do educador com relação aos participantes, sendo que este não se coloca como o único detentor do conhecimento.

\section{O empoderamento das mulheres}

Ao analisar a conjuntura das mulheres na sociedade, percebe-se que estas foram oprimidas desde a Antiguidade por uma cultura tradicionalmente patriarcal, marcada pela desigualdade de gênero. Essa circunstância impôs diversas dificuldades na trajetória pessoal e profissional feminina que, aos poucos, foi se modificando, mas ainda enfrenta muitos desafios. O desejo de transformar essa situação deu origem ao conceito de empoderamento feminino, que busca o reconhecimento e valorização das mulheres como forma de alcançar sua emancipação e a igualdade entre os gêneros (MELO; LOPES, 2012).

A palavra empoderamento derivou-se da tradução do termo empowerment, utilizado no meio organizacional para referir-se à atribuição ou transferimento de poderes a alguém, como forma de encorajar os indivíduos e equipes a comprometer-se mais com os resultados das organizações (MARTINS, 2003). Entretanto, de acordo com Deere e Leal (2002), este termo apresenta diversos significados e aplicações, dependendo do contexto ou perspectiva utilizados, podendo ser interpretado como emancipação e trajetória rumo ao poder sociopolítico ou como a busca pelo domínio sobre a própria vida e futuro do indivíduo.

Na perspectiva feminista, o empoderamento de mulheres é entendido como o processo da conquista da autonomia, da autodeterminação, implicando, portanto, na libertação das mulheres das amarras da opressão de gênero e patriarcal. Neste sentido, o objetivo maior de ações voltadas para este conceito é propiciar as condições para que elas possam questionar, desestabilizar e se organizar com vistas à erradicação da ordem patriarcal vigente 
(SARDENBERG, 2009). Conforme Melo e Lopes (2012), reivindica-se o fim da dominação masculina e seus privilégios sobre as mulheres, garantindo-as autonomia e controle de seus próprios corpos, sexualidade, ideologias e direitos, com a finalidade, segundo Prá (2006), de alcançar a igualdade de gênero, tanto em relação ao acesso aos recursos quanto aos benefícios.

Já na perspectiva das mulheres no espaço de trabalho, o empoderamento feminino fundamenta-se, de acordo com Melo e Lopes (2012), na busca pela emancipação pessoal e financeira, da qual, para Machado (2002), é um desejo tão relevante quanto à maternidade e ao matrimônio. Para isso, a mulher empenha-se em preparar-se e qualificar-se para o mercado laboral, a fim de desenvolver sua própria identificação e planejar seu futuro de acordo com seus desejos e não de outrem (MELO; LOPES, 2012).

O empoderamento feminino passa por vários caminhos: na sociedade, pelo conhecimento dos direitos da mulher, por sua inclusão social, instrução, profissionalização, consciência de cidadania e, também, "por uma transformação no conceito que ela tem dela mesma, em sua autoestima" (FERRARI, 2013, p. 2). Nesse sentido, Stromquist (1997) defende que isso ocorre por meio da construção de uma autoimagem e confiança positiva, do desenvolvimento da habilidade para pensar criticamente, da construção da coesão de grupo, da promoção da tomada de decisões e, por fim, da ação executada por elas.

Dessa forma, pode-se inferir que o enfoque dado ao conceito está relacionado ao fortalecimento dos atores sociais, por meio da existência de oportunidades sociais, políticas e econômicas, no sentido dado por Amartya Sen (2000) de expansão das capacidades humanas e das liberdades reais. Segundo o autor, a condição de agente dos indivíduos (em particular, as mulheres) é central para lidar com as privações materiais e não materiais a que se encontra submetida uma vasta parcela da população humana. Sob essa abordagem, portanto, os indivíduos são vistos como "agentes de mudança, e não como recebedores passivos de benefícios" (SEN, 2000, p. 11).

Embora Sen não utilize a designação de empoderamento, pode-se inferir semelhança a essa noção ao processo que ele descreve, e na relevância concedida ao aspecto de condição de agente individual, entendido como o de alguém que age ocasionando mudanças, sendo guiado por seus próprios valores e objetivos. Nessa condição de agente, está embutido o potencial de cada pessoa de cuidar de si mesma, isto é, a posição do indivíduo como sujeito do seu próprio desenvolvimento e a capacidade de influenciar o seu entorno como catalizador de transformações sociais. 
Dessa forma, este aporte teórico vinculado aos processos de empoderamento busca referendar o projeto de extensão "Multiplicadores de conhecimentos na agricultura familiar", que teve por objetivo propiciar as condições de para o seu desenvolvimento e atuação das mulheres nas organizações sindicais, políticas e comunitárias.

\section{O Coletivo de Mulheres do Sindicato Unificado dos Trabalhadores na Agricultura Familiar - SUTRAF-AU}

A igualdade de direitos e de oportunidades entre as pessoas tem se constituído na missão norteadora de organismos e instituições que pautam as suas ações pelo ideal de construção de uma sociedade democrática e cidadã. Embora esses direitos e garantias estejam presentes na Constituição Federal, as desigualdades persistem, pois os mesmos ainda encontram muitos obstáculos para se efetivarem e se concretizarem na prática. Isso porque a conquista de direitos decorre não só de sua presença nos diplomas legais, mas também de um processo permanente de conquista das mudanças sociais, com a participação ativa de toda a sociedade

Ao longo da história, as mulheres agricultoras familiares foram persistentes na luta pelos seus direitos, além de buscarem melhores condições de trabalho e de reconhecimento do engajamento no cenário político. Dessa forma, não se pode enquadrá-las na semântica que elas ocupam um papel secundário na sociedade. Mas sim, ressaltar a importância das mulheres ao designar parte de seu tempo para se dedicar em ações coletivas por meio da atuação como lideranças sindicais, políticas e comunitárias.

Diante deste contexto, o SUTRAF-AU tem como eixo de trabalho discutir o papel da mulher na sociedade, reconhecendo-as como protagonista na geração e cuidado da vida, na garantia da soberania alimentar, do cuidado com a saúde, da gestão e organização da propriedade rural, de geração de renda e na participação política.

O SUTRAF-AU atua em 27 municípios da Região Alto Uruguai (RS), com 24 sedes municipais, o trabalho desenvolvido com as mulheres agricultoras ocorre por meio do Coletivo Regional e dos Coletivos Municipais de Mulheres. O Coletivo de Mulheres tem por objetivo proporcionar às agricultoras o reconhecimento social na afirmação da autoestima, na participação da organização da produção agrícola na propriedade e na construção de políticas públicas para a agricultura familiar. Desta forma, as mulheres mantêm sua organização nos sindicatos tendo por meta incentivar mais mulheres a se organizarem, envolvendo em

\footnotetext{
\begin{tabular}{l|l}
\multirow{2}{*}{ REVISTA } & EXTENSÃO \& CIDADANIA \\
\cline { 2 - 3 } & v. 8, n. 14, p. 93-107, jul./dez. 2020. ISSN 2319-0566
\end{tabular}
} 
discussões por novas políticas públicas, atuando também na organização de ações em prol da agricultura familiar.

Com isso, o Coletivo de Mulheres do SUTRAF-AU juntamente com a UERGS, Unidade em Erechim, desenvolveram no ano de 2017, o projeto de extensão intitulado "Multiplicadores de conhecimentos na agricultura familiar", que teve por objetivo desenvolver oficinas de capacitação das mulheres agricultoras familiares, para empoderá-las a atuar nas organizações sindicais, políticas e comunitárias.

Os objetivos específicos do projeto de extensão foram:

(a) instrumentalizar o Coletivo de Mulheres de como organizar e conduzir reuniões e encontros;

(b) desenvolver a habilidade do trabalho em equipe e formação de lideranças dentro das comunidades para a organização social;

(c) realizar a sensibilização socioambiental entre as participantes;

(d) orientar e incentivar o cultivo e a utilização de plantas bioativas;

(e) instruir as mulheres sobre a importância da saúde e alimentação no meio rural;

(f) incentivar o resgate da produção de artesanatos temáticos rurais.

A formação contou com 28 participantes de 15 municípios da região Alto Uruguai, sendo que, ao final das oficinas, foi firmado o compromisso com as mulheres que participaram para que se tornem multiplicadoras, replicando a oficina nos seus municípios de origem para difundir as informações e conhecimentos obtidos durante os encontros, aproximando o público feminino das organizações sindicais.

\section{Os eixos de formação do projeto de extensão}

O primeiro eixo de formação propiciado pelo projeto de extensão foi a formação política das participantes, que ocorreu por meio da exposição e discussão dos seguintes temas: a) Previdência Social (o que mudaria na proposta regimental da previdência social para os agricultores familiares e quais seriam os impactos negativos e positivos da implementação da nova lei). O objetivo dessa etapa foi levar as mulheres a conhecerem os principais temas em discussão no cenário político. A formação política propiciou às participantes um repertório de informações que lhes permitiu compreender as nuances dos debates acerca da reforma da

\footnotetext{
\begin{tabular}{l|l}
\multirow{2}{*}{ REVISTA } & EXTENSÃO \& CIDADANIA \\
\cline { 2 - 3 } & v. 8, n. 14, p. 93-107, jul./dez. 2020. ISSN 2319-0566
\end{tabular}
} 
previdência social no país.

No eixo de Formação Motivacional foi destacada a importância do papel das mulheres no comportamento a ser adotado para a condução das atividades nos municípios, assim como a relevância do papel que exercem nos coletivos municipais. As ações desse eixo contemplaram: a) aspectos da liderança e motivação na condução de equipes de trabalho; b) como conduzir oficinas e reuniões dos coletivos; c) a aplicação de dinâmicas de grupo, para animar e sensibilizar os coletivos de mulheres; d) comunicação e desenvoltura para conduzir as atividades. Os resultados dessa etapa puderam ser visualizados por meio do engajamento das participantes em replicar os ensinamentos proporcionados pelo curso às demais mulheres agricultoras que participam nos Coletivos de Mulheres nos municípios.

No eixo Motivacional também foram promovidas atividades relacionadas à saúde da mulher, por meio da temática do Outubro Rosa. O objetivo da atividade foi de levar conhecimentos sobre os principais tipos de câncer que acometem as mulheres, explicando sobre os principais fatores que influenciam no desenvolvimento desta doença, bem como os cuidados para prevenção, apontados por especialistas.

Nesta etapa foram desenvolvidas atividades em 20 municípios de abrangência do SUTRAF-AU, a partir da organização de cada coletivo municipal, realizou-se encontros com palestras sobre a saúde da mulher e, também, oficinas de beleza para as participantes. Para cada participante da atividade foram entregues uma camiseta e folderes que abordaram a importância dos cuidados com a saúde da mulher agricultora rural.

Além dessas atividades municipais, também foi promovida uma atividade regional pelo Coletivo de Mulheres que realizou o II Encontro Regional de Mulheres Agricultoras Familiares tendo como tema "Mulheres lutando por direito, igualdade e respeito". O evento ocorreu em Erechim (RS), onde participaram cerca de 1000 mulheres agricultoras familiares de todos os municípios participantes do projeto. Na atividade, foram debatidos os temas relacionados à banalização da violência contra a mulher, o machismo, o feminicídio, o preconceito e a necessidade de as mulheres assumirem o protagonismo na busca por uma sociedade melhor. As Figuras 1 e 2 apresentam as atividades desenvolvidas neste evento.

Figura 1 - II Encontro Regional de Mulheres Agricultoras Familiares Erechim (RS) 


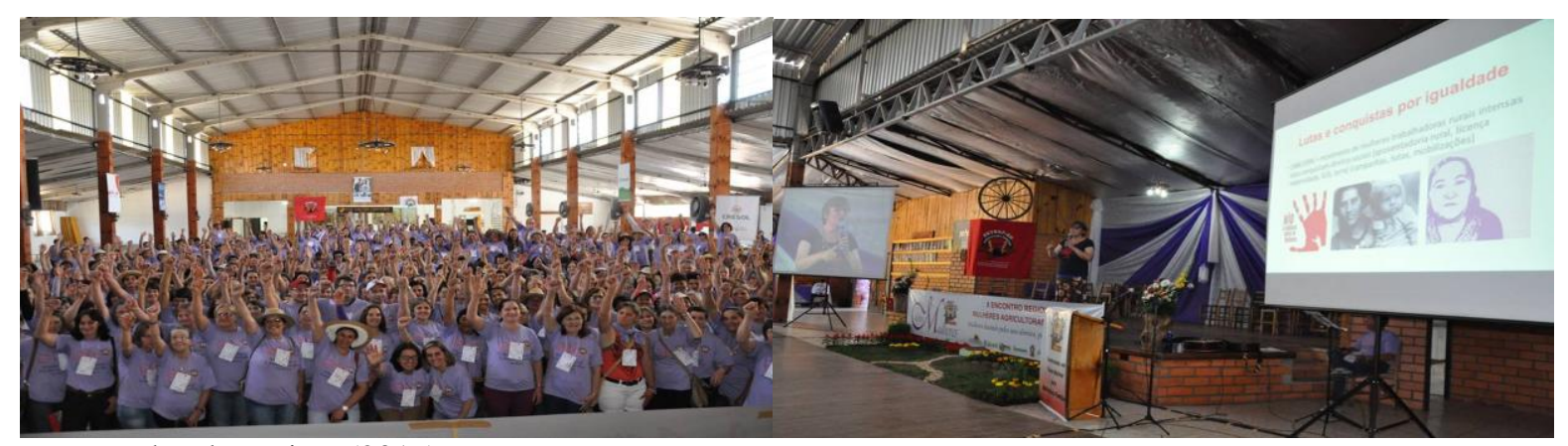

Fonte: Dados do projeto (2017).

As questões ambientais foram abordadas por meio de um eixo específico da formação. Nesta etapa, as mulheres tiveram a oportunidade de debater sobre os problemas ambientais ocasionados pela destinação inadequada de resíduos sólidos e líquidos no meio ambiente.

Segundo Mota et al. (2009), o descarte impróprio dos resíduos pode afetar o solo, a água e/ou o ar, a poluição do solo pode alterar suas características físico-químicas, representando uma séria ameaça à saúde pública, tornando o ambiente propício para o desenvolvimento de transmissores de doenças. A poluição da água pode alterar as características do ambiente aquático, por meio da percolação do líquido gerado pela decomposição da matéria orgânica presente no lixo, associado com as águas pluviais e nascentes existentes nos locais de descarga dos resíduos. Enquanto que a poluição do ar pode provocar a formação de gases naturais na massa de lixo, pela decomposição dos resíduos com e sem a presença de oxigênio no meio, originando riscos de migração de gás, explosões e até de doenças respiratórias, se estiverem em contato direto com os mesmos.

Por isso, na oficina de sensibilização também foram ministradas informações sobre separação e armazenamento adequado de resíduos, bem como o possível reaproveitamento de alguns resíduos como as embalagens de refrigerante e de vidros, demostrando como podem ser reaproveitados e utilizados no cotidiano familiar, por meio da confecção de pufes de garrafa pet e a decoração de vidros para a armazenagem de objetos, conforme as Figuras 3 e 4. 
Figura 2 - Confecção de pufes de garrafa pet e decoração de vidros

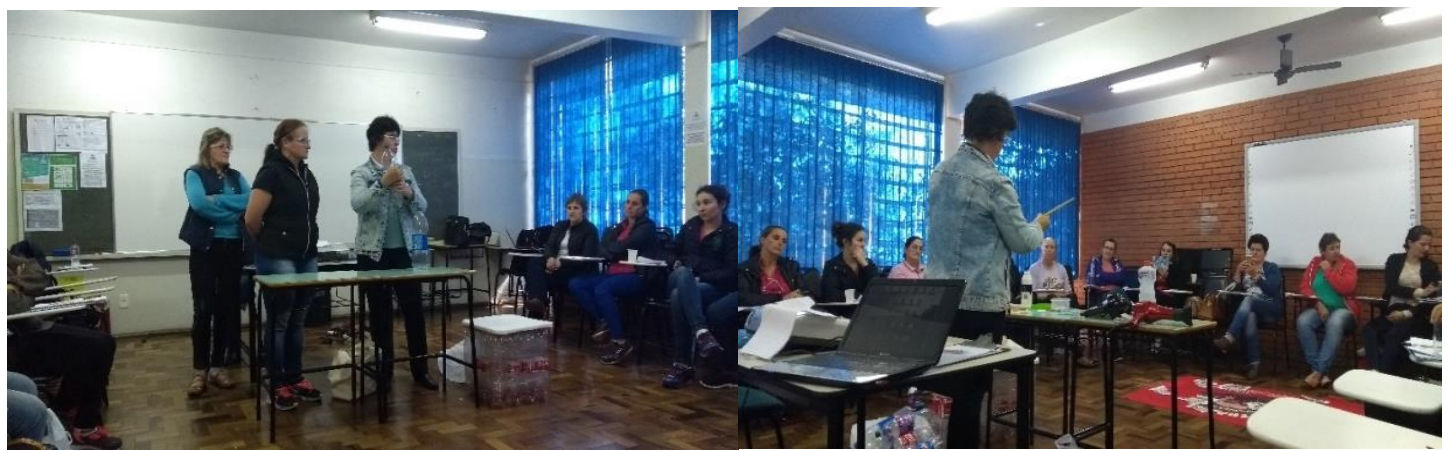

Fonte: Dados do projeto (2017).

Os resultados após a realização dessa prática foi o conhecimento adequado de como proceder a separação dos resíduos sólidose a importância do reaproveitamento dos materiais. Também se visualizou uma nova fonte de renda, importante para auxiliar na independência financeira, além de se perceber o empenho das participantes em desenvolver esta oficina nos coletivos municipais, levando o debate sobre a necessidade de identificar, separar e descartar adequadamente os resíduos nas propriedades rurais.

O eixo Cultural propiciado pelo projeto de extensão ocorreu por meio da aplicação de duas oficinas de artesanato. A primeira oficina foi a confecção de artesanatos com sementes, em que as participantes desenvolveram um enfeite de geladeira, conhecido também como mandala. A segunda atividade envolveu a temática natalina, com a construção de guirlanda, utilizando materiais disponíveis no meio rural como sementes, flores, cascas, palhas e outros elementos, conforme as Figuras 3 e 4 a seguir:

Figuras 3 e 4 - Confecção de enfeite de geladeira - mandala de sementes e guirlanda para o Natal

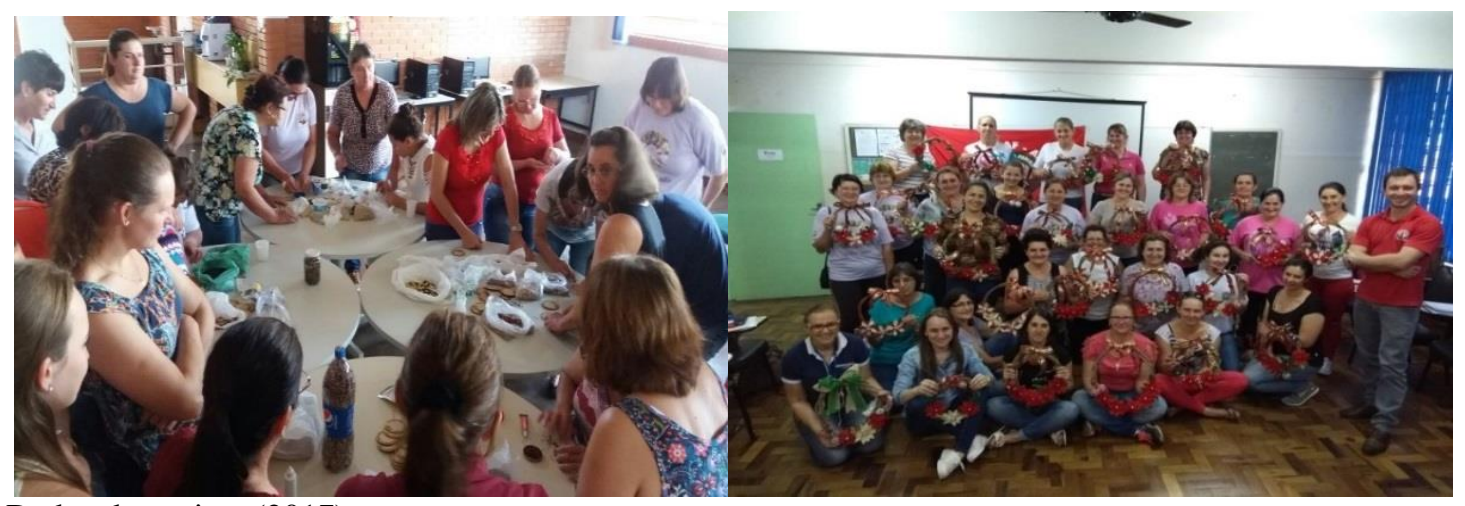

Fonte: Dados do projeto (2017). 
O objetivo dessa etapa foi incentivar o resgate da produção de artesanatos temáticos rurais e o desenvolvimento de novas habilidades artesanais, a partir destas oficinas, foi possível estimular a troca de experiência entre as participantes, incentivando a confecção de artesanatos como uma forma de gerar renda extra.

\section{Potencialidades e dificuldades identificadas neste processo de formação}

A proposta deste projeto de extensão de formação de multiplicadores de conhecimento, foi de promover a atuação das participantes na disseminação de informações, formando novas agentes sindicais engajadas no desenvolvimento rural sustentável. Por isso, um dos primeiros aspectos positivos foi a organização das participantes para realizarem oficinas em seus municípios, as participantes fizeram reuniões para passar informações do Coletivo de Mulheres, juntamente com a realização de uma prática para construção dos conhecimentos atrelados ao tema da oficina.

Uma das primeiras oficinas replicadas foi a prática que discutiu a sensibilização socioambiental por meio da construção de pufes de garrafa pet e o reaproveitamento de vidros para a decoração de ambientes, conforme podem ser visualizados nas Figuras 5 e 6.

Figuras 5 e 6 - Participantes do projeto repassando a técnica da confecção do pufe de garrafa pet nos municípios de São Valentim e Três Arroios (RS)

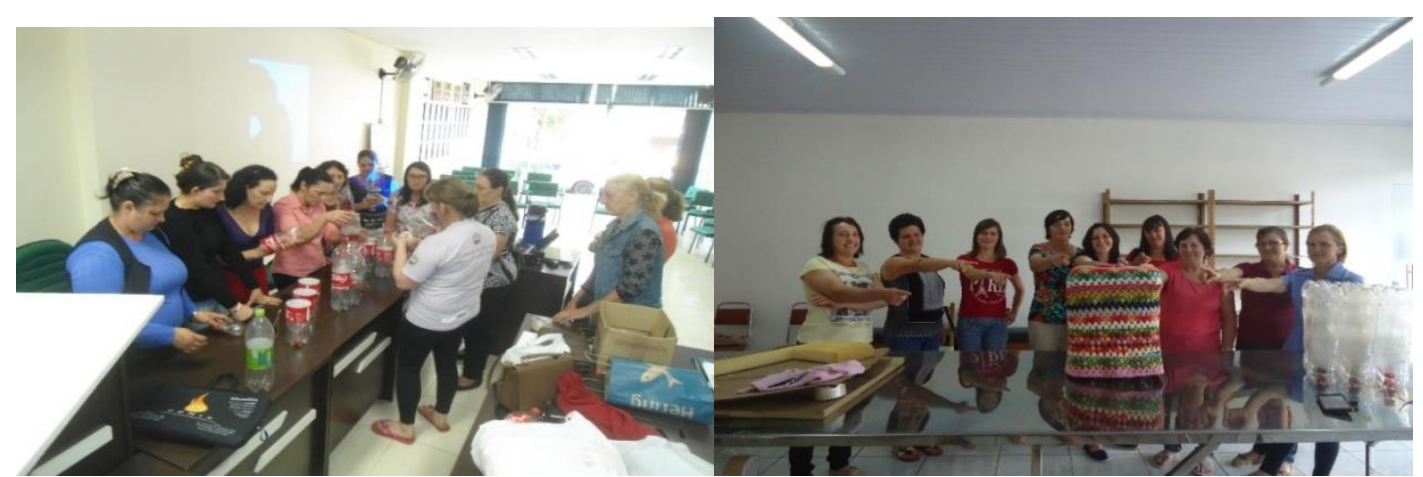

Fonte: Dados do projeto (2017).

A segunda oficina replicada nos municípios foi a confecção de mandalas de sementes e de guirlandas natalinas, conforme Figuras 7 e 8. 
Figuras 7 e 8 - Participantes do projeto repassando a atividade de confecção de mandalas nos municípios de Aratiba e Jacutinga (RS)

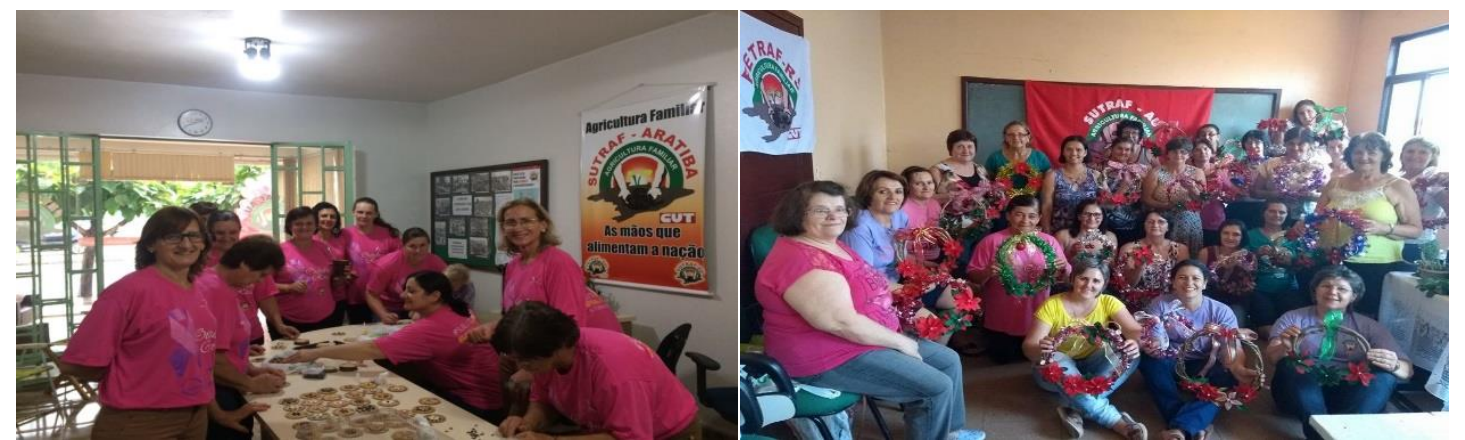

Fonte: Dados do projeto (2017).

A partir da replicação destas oficinas, foi possível estimular a troca de experiências entre as participantes, incentivando a confecção de artesanatos utilizando os materiais disponíveis no meio rural, potencializando o artesanato rural como uma forma de gerar renda extra. Os resultados alcançados abrangeram um público diretamente de mais de 200 pessoas, informando e auxiliando na divulgação e discussão da importância do autoexame e dos exames de rotina que devem ser feitos para diagnosticar o câncer com antecedência. Essas oficinas podem ser vistas nas Figuras 9 e 10 a seguir:

Figuras 9 e 10 - Atividade Outubro Rosa desenvolvida na cidade de Viadutos e Campinas do Sul (RS)

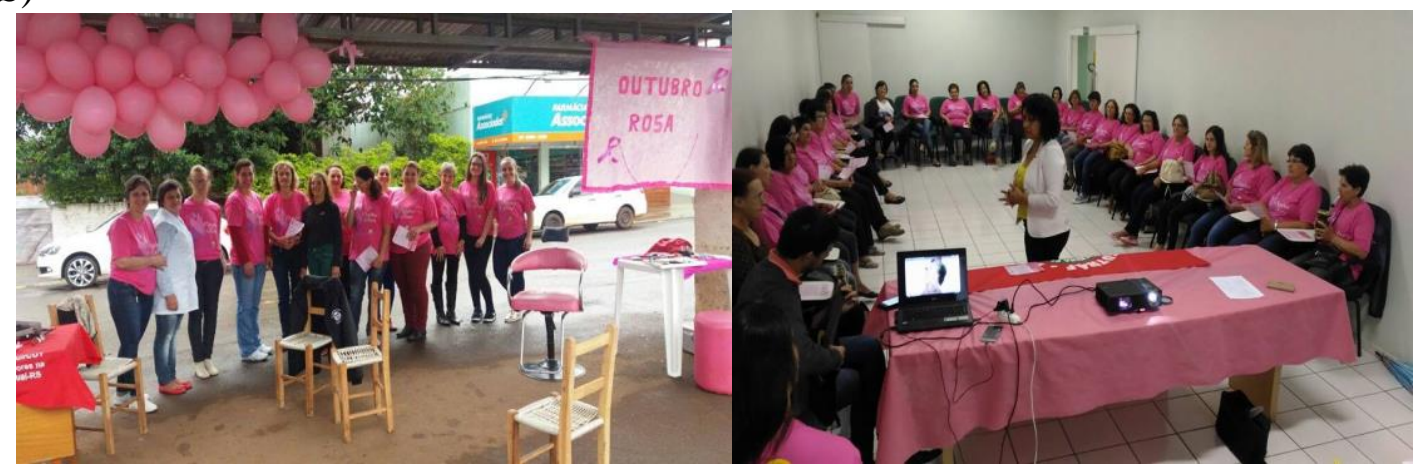

Fonte: Dados do projeto (2017).

No decorrer do projeto, pode-se identificar alguns aspectos que desafiam o maior envolvimento e participação das mulheres. A grande maioria não possui consciência sobre sua

$$
\begin{array}{l|l}
\multirow{2}{*}{\text { REVISTA }} & \text { EXTENSÃO \& CIDADANIA } \\
\cline { 2 - 3 } & \text { v. 8, n. 14, p. 93-107, jul./dez. 2020. ISSN 2319-0566 }
\end{array}
$$


independência ou mesmo da importância de sua participação nas atividades da comunidade ou do sindicato. As mulheres acreditam ser somente de sua responsabilidade os afazeres do lar, o cuidado e atenção dos filhos e marido. Acreditando também que a função da representação e ocupação dos espaços sociais é de responsabilidade apenas do homem. Nas relações familiares destas mulheres, observa-se como a ordem de gênero patriarcal ainda impera e é mantida cotidianamente por homens e mulheres (SAFFIOTI, 1992).

Apresentam-se ainda como dificuldades na execução do projeto, o deslocamento para o local onde eram desenvolvidas as oficinas, pois a grande maioria das mulheres agricultoras não possuem Carteira Nacional de Habilitação $(\mathrm{CNH})$, o que dificulta a locomoção para o desenvolvimento das atividades. Além disso, outro fator limitante é a questão da sobrecarga de atividades que elas precisam realizar durante o dia nas propriedades rurais que, muitas vezes, gera um sentimento de impotência, pois precisam estar em diferentes espaços ao mesmo tempo, e, por isso, algumas ainda acabam priorizando as atividades na propriedade rural.

A partir dessas limitações identificadas, o Coletivo de Mulheres, juntamente com a UERGS, pretende dar continuidade ao projeto de extensão, mas realizando atividades com um cronograma pré-definido. A estratégia buscará realizar oficinas de curta duração com execução a cada dois meses, permitindo às mulheres o planejamento e a priorização dos dias préestabelecidos para as atividades de formação.

\section{Considerações finais}

A realização deste trabalho permitiu descrever como o Curso de Extensão "Multiplicadores de conhecimento na agricultura familiar" foi realizando entre as instituições UERGS e o SUTRAF-AU. Os principais eixos norteadores do projeto foram: formação política, que proporcionou às mulheres o conhecimento sobre as regras da proposta de reforma da Previdência Social; o segundo eixo foi o Motivacional, em que foram trabalhados alguns aspectos de liderança e motivação, além de atividades relacionadas à saúde da mulher, por meio da temática do Outubro Rosa. O terceiro eixo de Formação, desenvolvido em torno das questões ambientaiscom o debate das participantes sobre os problemas ambientais ocasionados pela destinação inadequada de resíduos sólidos e líquidos no meio ambiente e, por fim, o eixo Cultural, que destacou a importância do resgate de artesanatos utilizados com materiais do cotidiano rural. 
As principais potencialidades alcançadas pelo projeto foram percebidas a partir da organização das participantes e no engajamento para replicar as oficinas nos coletivos municipais. As maiores dificuldades identificadas se encontram na formação da consciência das participantes sobre a importância em romper o padrão patriarcal e dedicar-se entre os afazeres domésticos e do campo aos processos de formação. A grande maioria das mulheres ainda não possui consciência sobre sua independência, ou mesmo da importância de sua participação nas atividades da comunidade ou do sindicato, pois existe um grande receio por parte das mulheres em assumir papéis de liderança.

E, por fim, a realização deste projeto de extensão foi de extrema importância para as instituições envolvidas, uma vez que foram promovidas ações de sensibilização e de formação para cerca de 200 mulheres agricultoras familiares, e infere-se que estas atividades propiciaram condições para que as participantes do Coletivo de Mulheres sejam as protagonistas de uma nova geração, na busca constante por empoderamento para reduzir as desigualdades de gênero existentes meio rural.

\section{Referências}

DEERE, C.; LEAL, M. O empoderamento da mulher: direitos à terra e direitos de propriedade na América Latina. Porto Alegre: Ed da UFRGS, 2002.

FERRARI, R. O empoderamento da mulher. Disponível em:

http://www.fap.sc.gov.br/notícias/empoderam ento.pdf. Acesso em: 19 fev. 2018.

FREIRE, P. Pedagogia da autonomia: saberes necessários à prática educativa. 8. ed. Rio de Janeiro: Paz e Terra, 1998.

MACHADO, H. Identidade empreendedora de mulheres no Paraná. 188 f. Tese (Doutorado em Engenharia de Produção) - Programa de Pós-Graduação em Engenharia de Produção, Universidade Federal de Santa Catarina, Florianópolis, 2002.

MARTINS, C. Trabalhadores na reciclagem do lixo: dinâmicas econômicas, socioambientais e políticas na perspectiva de empoderamento. $210 \mathrm{f}$. Tese (Doutorado em Sociologia) - Programa de Pós-Graduação em Sociologia, Universidade Federal do Rio Grande do Sul, Porto Alegre, 2003.

MELO, M.; LOPES, A. Empoderamento de mulheres gerentes: a construção de um modelo teórico de análise. Revista Gestão e Planejamento, Salvador, v. 12, n. 3, p. 648-667, 2012. 
MOTA, C. J. et al. Características e impactos ambientais causados pelos resíduos sólidos: uma visão conceitual. I CONGRESSO INTERNACIONAL DE MEIO AMBIENTE SUBTERRÂANEO. Anais... São Paulo, 2009.

PRÁ, J. Políticas públicas, direitos humanos e capital social. In: BAQUERO, M.;

CREMONESE, D. (org.). Capital Social: teoria e prática. Ijuí: Ed. da Unijuí, 2006.

SAFFIOTI, B. I. H. Gênero, patriarcado, violência. São Paulo: Fundação Perseu Abramo, 2004.

SARDENBERG, M. B. C. Conceituando "empoderamento" na perspectiva feminista.

Salvador: NEIM/UFBA, 2009.

SEN, A. Desenvolvimento como liberdade. São Paulo: Companhia das Letras, 2000.

SIQUEIRA, S. S. E. A. Empoderamento de mulheres agricultoras: possibilidades e limites de um projeto de desenvolvimento rural no semiárido baiano. $18^{\circ}$ REDOR. Anais... Recife,2014.

STROMQUIST, N. La busqueda del empoderamiento: en qué puede contribuir el campo de la educación. In: LEÓN, M. Poder y empoderamiento de las mujeres. Santafé de Bogotá,

Colômbia: TM Editores, 1997.

Recebido em: 2 de julho de 2018.

Aceito em: 14 de outubro de 2020. 